\title{
Acacia Tortilis Seeds as a Green Chemistry Adsorbent to Clean up the Water Media from Cadmium Cations
}

\author{
M. A. Ackacha and S. A. Meftah
}

\begin{abstract}
The potential use of Acacia tortilies seeds as a new green chemistry adsorbent to reduce cadmium cations from water was evaluated through batch experiments. The Acacia tortilies seeds were characterized by determination of solubility in water and determination of surface area and pore volume as well as determination of cellulose content. The important parameters which affect the adsorption process, such as initial pH, contact time and contact temperatures were studied. The maximum adsorption capacity occurs at pH 3.4 after 2 hours. Two isotherm models include Langmuir and Freundlich were investigated. The maximum adsorption capacity obtained were 706,807 and $1004 \mathrm{mg} / \mathrm{g}$ at 293,303 and $323 \mathrm{~K}$, respectively. Experimental data were also performed to the first-order, pseudo-second order and intra-particle diffusion kinetic models. The results indicated that the adsorption of cadmium cations onto Acacia tortilies seeds followed well second-order kinetics. Thermodynamic parameters, $\Delta G^{\mathrm{o}}, \Delta H^{\mathrm{o}}$ and $\Delta S^{\mathrm{o}}$ indicated the cadmium cations sorption to be endothermic and spontaneous with increase randomness at solid-solution interface. The adsorption mechanism of cadmium cations onto Acacia tortilies seeds was interpreted. A comparison between adsorption capacity of Acacia tortilies seeds and adsorption capacities of other low cost adsorbents were presented. It was found that, the adsorption capacity of Acacia tortilies seeds was higher than the adsorption capacities of all other low cost adsorbents indicated in this research.
\end{abstract}

Index Terms-Acacia tortilis, adsorption, Langmuir, pseudo second order, cadmium.

\section{INTRODUCTION}

Cadmium is considered as to be hazard metal because of its toxicity and accumulation in the food chain. Cadmium is not biodegradable; therefore it causes several health problems such as itai-itai disease, renal damage and hypertension, damage to the kidneys, lungs, and liver. The World Health Organization (WHO) and the American Water Works Association (AWWA) have recommended that the maximum permissible level for cadmium in drinking water is 0.005 $\mathrm{mg} / \mathrm{l}[1]$. The various techniques that could be used to remove dissolved heavy metal cations from wastewaters include oxidation, reduction, precipitation, ion exchange [2]. These techniques have disadvantages due to incomplete metal removal, high energy requirement, generation of toxic wastes and the need of expensive equipment [3]. Adsorption technique is also used for metal removal from aqueous solution. Various agricultural wastes as coconut coirpith, sawdust, rice husk, banana pith and apple wastes were used

Manuscript received September 10, 2013; revised November 11, 2013.

M. A. Ackacha is with Chemistry Department, Faculty of Science, Sebha University, P. O. Box 625 (e-mail: ackacha57@yahoo.com).

S. A. Meftah is with the Secondary school, Samno, Sebha, Libya. as low cost adsorbents [2].

The aim of this research was to evaluate the performance of Acacia tortilies seeds as a new green adsorbent to remove cadmium cations from water media.

\section{MATERIALS AND METHODS}

\section{A. Materials}

Acacia tortilis seeds were treated with natural lemon juice (NLJ) which was obtained from lemon according to the method indicated in our previous work, except that the ratio of NLJ to water was $1: 1$ instead of $0.5: 1$ [4]. Cadmium chloride salt, xylenol orange dye and hexamethylene tetra amine were ordered from Merck, Germany. Hydrochloric acid and sodium hydroxide were purchased from Fluka, Germany. Ethylene diamine tetra acetic acid (EDTA) was supplied by Riedel Dehean AG-Hannover, England. The nitrogen adsorption apparatus (Nova 2200 Quntachrome Corporation, USA) was used to determine the surface area and pore volume of adsorbent. The $\mathrm{pH}$ instrument (JENWAY 3205 , USA) was used to determine the cadmium solutions $\mathrm{pH}$.

\section{B. Methods}

The percentage of solubility of the Acacia tortilis seeds in water was measured as indicated in literature [5].

Synthetic stock solution of cadmium cations was prepared by dissolving $1 \mathrm{~g}$ of annular grade salt of cadmium chloride in $1000 \mathrm{ml}$ of distilled water. The stock solution was further diluted with distilled water to the desired concentrations for obtaining the work solutions. Determination of initial concentration $\left(C_{\mathrm{o}}\right)$ and concentrations at equilibrium $\left(C_{e}\right)$ of cadmium cations solutions were carried out by titration with EDTA using xylenol orange dye as indicator [6].

The adsorption process was carried out through batch experiments [7]. The adsorption capacity of cadmium cations onto Acacia tortilis seeds at equilibrium $\left(q_{e}\right)$ was determined by the following equation [8]:

$$
q_{e}=\frac{\left(C_{\mathrm{o}}-C_{e}\right) \times V}{W}
$$

where $V(1)$ is the volume of the solution and $W$ is the weight of the adsorbent $(g)$.

The cellulose content of Acacia tortilis seeds were measured as follows [9]: A certain weight of Acacia tortilis seeds $\left(W_{1}\right)$ was dissolved in $100 \mathrm{ml} \mathrm{HCl}(2 N)$ and boiled for 2 hours The mixture was filtrated and the filtrate was washed with distilled water for 3-5 times, dried and weighed $\left(W_{2}\right)$. 
The cellulose content $(\%)$ in the sample was calculated according to the following equation:

$$
\frac{W_{1}-W_{2}}{W_{1}} \times 100
$$

\section{RESUltS AND DISSECTION}

\section{A. Characterization of Acacia Tortilis Seeds}

As presented in Table I, the treated Acacia tortilis seeds with NLJ can be used as adsorbent material in aqueous solutions due to their low solubility in water $(3.2 \%)$. One can also observe from Table I that, the decrease of the surface area from $640 \mathrm{~m}^{2} / \mathrm{g}$ to $480 \mathrm{~m}^{2} / \mathrm{g}$ and the decrease of volume pore from $0.405 \mathrm{ml} / \mathrm{g}$ to $0.312 \mathrm{ml} / \mathrm{g}$ are due to the adsorption of cadmium cations onto Acacia tortilis seeds. It can also be noticed from Table I, that the content of cellulose in Acacia tortilis seeds was $75 \%$. This result led us to use this sample as adsorbent material due to the presence of more functional groups in the structure of their cellulose.

TABLE I: CHARACTERIZATION OF ACACIA TORTILIS SEEDS

\begin{tabular}{lcc}
\hline \hline Character & Treated sample & Treated sample with Cd(II) \\
\hline Solubility in water $(\%)$ & 3.2 & - \\
Surface area $\left(\mathrm{m}^{2} / \mathrm{g}\right)$ & 640 & 480 \\
Pore volume $(\mathrm{ml} / \mathrm{g})$ & 0.405 & 0.312 \\
Cellulose content $(\%)$ & 75 & - \\
\hline \hline
\end{tabular}

\section{B. Influence of Initial $p H$}

The $\mathrm{pH}$ of aqueous solution is the most important parameter in the adsorption process [10]. Adsorption of cadmium cations onto Acacia tortilis seeds as a function of $\mathrm{pH}$ is presented in Table II. The maximum adsorption capacity occurs at $\mathrm{pH} 3.4$ but adsorption decreases when $\mathrm{pH}$ is increased further. The applied optimum conditions are as follows: contact temperature, $30 \mathrm{C}^{\circ}$; contact time, 30 minutes; initial concentration, $200 \mathrm{mg} / \mathrm{l}$ and adsorbent dose, $0.1 \mathrm{~g} / 1$.

The decrease of adsorption capacity after optimum initial $\mathrm{pH}$ may be due to the precipitation of cadmium cations as hydroxides [11].

TABLE II: INFLUENCE OF INITIAL PH ON ADSORPTION CAPACITY

\begin{tabular}{lc} 
Initial $\mathrm{pH}$ & $q_{e}(\mathrm{mg} / \mathrm{g})$ \\
\hline 2.3 & 36 \\
3.4 & 90 \\
4.2 & 65 \\
5.1 & 61 \\
\hline \hline
\end{tabular}

\section{Influence of Contact Time}

The dependence of adsorption of cadmium cations onto Acacia tortilis seeds with contact time for initial cadmium cations concentration of $200 \mathrm{mg} / \mathrm{l}$, adsorbent dose of $\mathrm{o} .1 \mathrm{~g} / \mathrm{l}$ at $30 \mathrm{C}^{\circ}$ and $\mathrm{pH} 3$ are shown in Fig. 1. The adsorption capacity was found to increase when the contact time increased and reached maximum value within 2 hours. There are no significant changes in adsorption capacity after 2 hours and therefore, the time for reaching equilibrium was set at 2 hours.

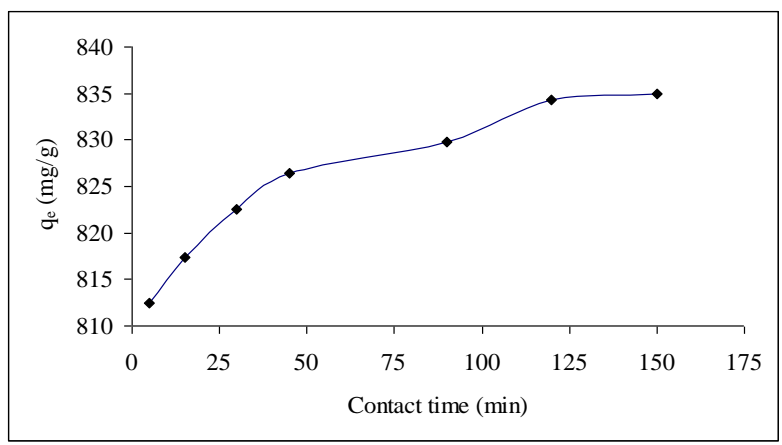

Fig. 1. Influence of contact time on adsorption capacity.

\section{Kinetic Studies}

The kinetic studies describe the rate of adsorption of metal cations onto adsorbent. This rate controls the equilibrium time [12].

To test the experimental data, three kinetic models: first order, pseudo second order and intra particle diffusion were used in the present research.

The first order equation is described by Lagergren as follows [13]:

$$
\log \left(q_{e}-q_{t}\right)=\log q_{e}-\frac{K_{1}}{2.303} t
$$

where $q_{t}$ refers to the amount of cadmium cations adsorbed per unit weight of adsorbent $(\mathrm{mg} / \mathrm{g})$ at time $t(\mathrm{~min})$. The value of $\mathrm{q}_{\mathrm{e}}$ and first order rate constant $\left(K_{1}\right)$ can be calculated from the plot of $\log \left(q_{e}-q_{t}\right)$ versus $t$ (Figure not shown). Table III displayed the first order parameters of cadmium cations onto Acacia tortilis seeds as well as the linear equation of the plot of $\log \left(q_{e}-q_{t}\right)$ versust .

TABLE III: FIRST ORDER PARAMETERS FOR THE ADSORPTION OF CADMIUM CATIONS ONTO ACACIA TORTILIS SEEDS AND LINEAR EQUATION

\begin{tabular}{ccccc}
\hline \hline$q_{e \exp }$ & $q_{e \text { calcu }}$ & $K_{1}(1 / \mathrm{min})$ & Linear equation & $R^{2}$ \\
\hline 835 & 22 & 0.0184 & $y=-0.008 x+1.3356$ & 0.9656 \\
\hline \hline
\end{tabular}

A pseudo second order equation was expressed by the following equation [13]:

$$
\frac{t}{q_{t}}=\frac{1}{K_{2} q_{e}^{2}}+\frac{1}{q_{e}} t
$$

The plot of $t / q_{t}$ versus $t$ (Figure not shown) could provide a linear relationship, from which $q_{e}$ and $K_{2}$ (pseudo second order constant) can be determined.

Table IV present the pseudo second order parameters of cadmium cations onto Acacia tortilis seeds as well as the linear equation of the plot $t / q_{t}$ versust.

TABLE IV: SECOND ORDER PARAMETERS FOR THE ADSORPTION OF CADMIUM CATIONS ONTO ACACIA TORTILIS SEEDS

\begin{tabular}{crccr}
\hline \hline$q_{e \exp }$ & $q_{e \text { calcu }}$ & $K_{2}(\mathrm{~g} / \mathrm{mg} . \mathrm{min})$ & Linear equation & $R^{2}$ \\
\hline 835 & 833 & 0.0048 & $y=0.0012+0.0005$ & 1 \\
\hline \hline
\end{tabular}


A comparison between Table III and Table IV proves that, the adsorption of cadmium cations onto Acacia tortilis seeds, follows the pseudo second order model. This is due to the high value of $R^{2}$ and also the values of calculated adsorption capacity $\left(q_{e}\right.$ calcu $)$ matched the experimental adsorption capacity $\left(q_{e}\right.$ exp. $)$.

The intra-particle diffusion equation is given as [13]:

$$
q_{t}=K_{p} t^{1 / 2}+C
$$

where $K_{p}$ is the intra-particle diffusion constant rate and can be obtained from the slop of the second portion of the straight line of plot $q_{e}$ versus $t^{1 / 2}$.

The adsorption was controlled by three different stages: the first sharper portion being a gradual adsorption, second linear portion where intra-particle diffusion is the rate limiting step and the last portion being the final equilibrium stage due to the law concentration of cadmium cations in solution phase and also due to the less adsorption sites onto the surface of the adsorbent. It is clear from Fig. 2, that the intra-particle diffusion is not the main determining step as the second linear potion of the plot $q_{e}$ versus $t^{1 / 2}$ did not pass through the origin point.

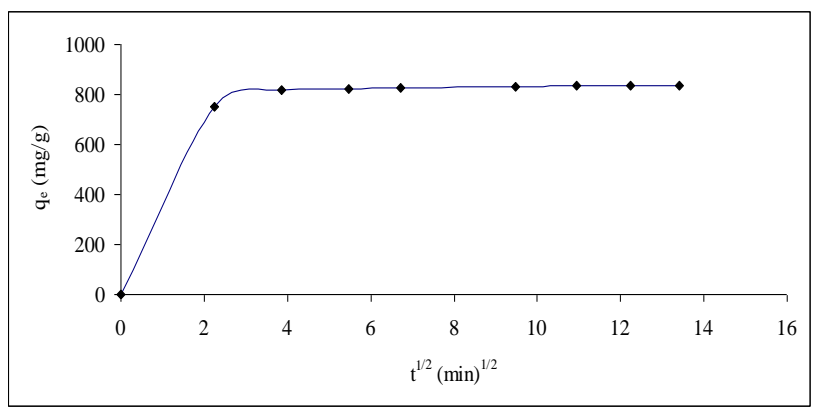

Fig. 2. Intra-particle diffusion plot of cadmium cations onto treated Acacia tortilis seeds.

\section{E. Sorption Isotherms}

Adsorption isotherms are very important since they represent the interaction between adsorbate and adsorbent [14]. The plots of $q_{e}$ versus $C_{e}$ made it possible to obtain the adsorption isotherm which is described by various mathematical models such as Langmuir, Freundlich and R-D isotherm. Therefore, in case of investigation the adsorption capacity of cadmium cations onto Acacia tortilis seeds, the experimental data should be fitted well to any of these isotherm models. The conditions of this adsorption isotherm are as follows: $\mathrm{pH}, 3$; particles diameter of Acacia tortilis seeds, 50-125 $\mu \mathrm{m}$; contact time, 2 hours and adsorbent dose, $0.1 \mathrm{~g} / \mathrm{l}$. The contact temperatures used in this adsorption isotherm studies were 293, 303 and $323 \mathrm{~K}$.

The equilibrium adsorption isotherms are one of the most important data for understanding the mechanism of the adsorption process. The Langmuir and Freunlich isotherms were selected in this study in order to fit the experimental data [15].

Langmiur adsorption isotherm is given by the following expression:

$$
\frac{C_{e}}{q_{e}}=\frac{1}{q_{\max } \cdot b}+\frac{1}{q_{\max }} C_{e}
$$

where $q_{\max }(\mathrm{mg} / \mathrm{g})$ and $b(\mathrm{l} / \mathrm{mg})$ are the Langmuir constants related to the maximum adsorption capacity and energy of adsorption, respectively. When $C_{e} / q_{e}$ is plotted against $C_{e}$, a straight line with the slop of $1 / q_{\max }$ and intercept of $1 / q_{\text {max.b }}$ are obtained (Fig. 3). The Langmuir constant, $K_{L}$ will be used later to calculate the Gibbs free energy of the adsorption process. $K_{L}$ was determined according to the following equation:

$$
K_{L}=q_{\max } \times b
$$

The parameters $q_{\max }, b, K_{L}, R_{L}$ and $R^{2}$ of cadmium cations adsorption at different contact temperatures are presented in Table V. It can be noticed on Table V that, the obtained data do not match langmuir isotherm due to the important difference between the $q_{e}$ exp and $q_{e}$ calcu and also due to the lower values of $\mathrm{R}^{2}$.

The essential feature of Langmuir model can be expressed in terms of a dimensionless constant separation factor or equilibrium parameter $\left(R_{L}\right)$ given by the following equation:

$$
R_{L}=\frac{1}{1+b \times C_{o}}
$$

For favorable adsorption, the value of $R_{L}$ should be in the range $0<R_{L}<1$ [16]. As shown on Table $\mathrm{V}$, the obtained data proved that, the shape of isotherm is favorable because the values of $R_{L}$ lie between 0 and 1 .

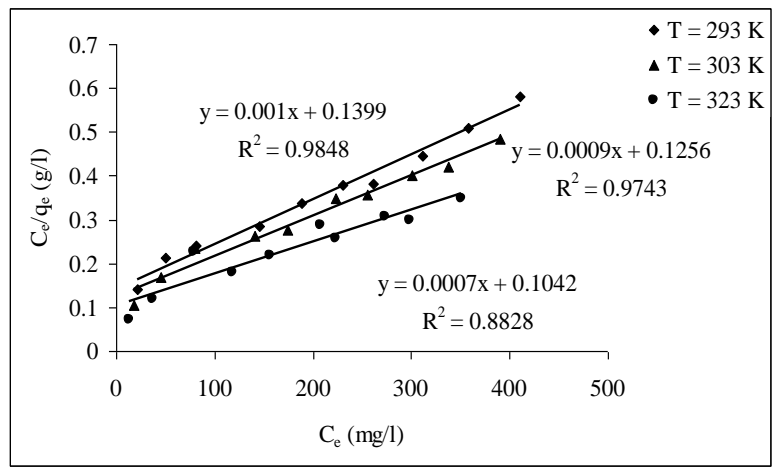

Fig. 3. Langmuir isotherms of cadmium cations onto treated Acacia tortilis seeds at various temperatures.

TABLE V: LANGMMUIR ISOTHERM CONSTANTS FOR THE ADSORPTION OF CADMIUM CATIONS ONTO ACACIA TORTILIS SEEDS AT VARIOUS TEMPERATURES

\begin{tabular}{lcccccc}
\hline \hline$T(K)$ & $\begin{array}{c}q_{e} \text { exp } \\
(\mathrm{mg} / \mathrm{g})\end{array}$ & $\begin{array}{c}q_{e \text { calcu }} \\
(\mathrm{mg} / \mathrm{g})\end{array}$ & $\begin{array}{c}b \\
(1 / \mathrm{mg})\end{array}$ & $\begin{array}{c}K_{L} \\
(1 / \mathrm{g})\end{array}$ & $R_{L}$ & $R^{2}$ \\
\hline 293 & 706 & 1000 & 0.0071 & 7.1 & $0.20-0.73$ & 0.9848 \\
303 & 807 & 1111 & 0.0072 & 8.1 & $0.20-0.73$ & 0.9743 \\
323 & 1004 & 1429 & 0.0067 & 9.6 & $0.21-0.74$ & 0.8828 \\
\hline \hline
\end{tabular}

The Freundlich expression was applied in the present study, as in

$$
\log q_{e}=\log K_{F}+\frac{1}{n} \operatorname{loq} C_{e}
$$

where $K_{F}$ and $\mathrm{n}$ are the Freundlich constants and are determined from the plots of $\log c_{e}$ versus $\log q_{e}$ (Fig. 4). $K_{F}$ 
indicate the adsorption capacity of the adsorbent and its values at all temperatures lie at a range of 28.7-44.5. The other Frendlich constant $\mathrm{n}$ is a measure of the deviation from linearity of the biosorption that the numerical values of $\frac{1}{n}$ at all temperatures lie between 0 and 1 (1.80-1.87), indicating that cadmium cations are favorably adsorbed by Acacia tortilis seeds at all temperatures [17]. The $\mathrm{R}^{2}$ values in case of Freundlich adsorption isotherm are higher when compared to Langmuir adsorption isotherm, and this means that the adsorption process at different temperatures is more favorable in case of Freundlich adsorption isotherm than Langmuir adsorption isotherm.

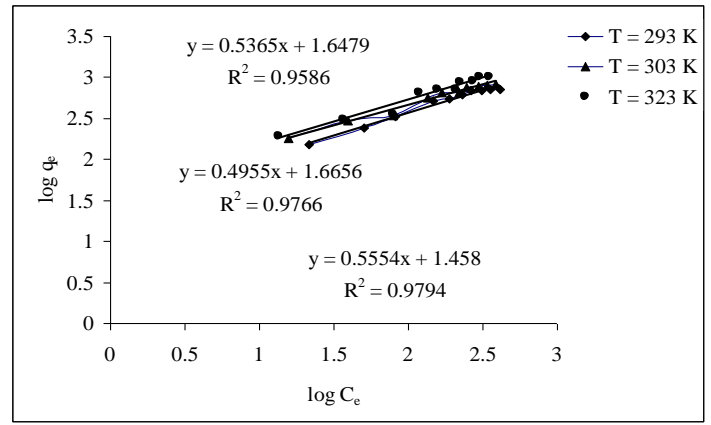

Fig. 4. Freunlich isotherms of cadmium cations onto treated Acacia tortilis seeds at various temperatures.

\section{F. Thermodynamic Studies}

Thermodynamic parameters such as standard free energy change $\left(\Delta \mathrm{G}^{\circ}\right)$; standard enthalpy change $\left(\Delta \mathrm{H}^{\circ}\right)$ and standard entropy change $\left(\Delta \mathrm{S}^{\circ}\right)$ can be calculated as $[18]$ :

$$
\begin{gathered}
\Delta G^{\circ}=-R T \ln K_{L} \\
\operatorname{Link}=\frac{\Delta S^{\circ}}{R}-\frac{\Delta H^{\circ}}{R T}
\end{gathered}
$$

where $R$ is universal gas constant $(8.314 \mathrm{kj} / \mathrm{mol})$.

The values of $\Delta H^{\circ}$ and $\Delta S^{\circ}$ were calculated respectively from the slope and intercept of the plots of $1 / T$ versus $\ln K$ as shown in Fig. 5. The negative values of $\Delta \mathrm{G}^{\circ}$ were $-4.77,-5.26$ and $-.6 .07 \mathrm{Kj} / \mathrm{mol}$ at 293, 303 and $323 \mathrm{~K}$, respectively. This result proved that, the adsorption process is spontaneous in nature and the spontaneity increases as the temperature increases. The positive value of $\Delta \mathrm{H}^{\circ}(8.1 \mathrm{Kj} / \mathrm{mol})$ indicates the endothermic nature of adsorption. The positive value of $\Delta \mathrm{S}^{\circ}(0.044 \mathrm{Kj} / \mathrm{mol})$ showed the increase randomness of the solid-liquid interface during the adsorption process.

\section{G. The Proposal Mechanism of Adsorption of Cadmium Cations onto Acacia Tortilis Seeds}

Natural agricultural adsorbent such as Acacia tortilis seeds have the ability to adsorb metal ions due to different functional groups present on their macromolecules, which include polysaccharides, lignin and other elements via complexation or ion-exchange. The adsorbent possesses acidic functional groups on surface such as $-\mathrm{COOH}$ and $-\mathrm{OH}$ that are responsible for the cation exchange property as expressed in the following equations:

$$
2-\mathrm{COOH}+\mathrm{M}^{2+}=-(\mathrm{COO}){ }_{2} \mathrm{M}+2 \mathrm{H}^{+}
$$

$$
2-\mathrm{COH}+\mathrm{M}^{2+}=-(\mathrm{CO}){ }_{2} \mathrm{M}+2 \mathrm{H}^{+}
$$

The adsorption cadmium cations onto the surface of Acacia tortilis seeds was attributed to the two following mechanisms:

1) Ion exchange mechanism between the anionic carboxyl groups in Acacia tortilis seeds and the cationic nature cadmium in solution.

2) Adsorption mechanism which may involve four steps according to the results obtained from intra-particle diffusion model:

- Migration of adsorbate from the bulk of the solution to the surface of the adsorbent.

- Diffusion of the adsorbate through the boundary layer to the surface of the adsorbent.

- Adsorption at active sites of the surface of Acacia tortilis seeds.

- Intra-particle diffusion of cadmium cations onto the interior pores of Acacia tortilis seeds.

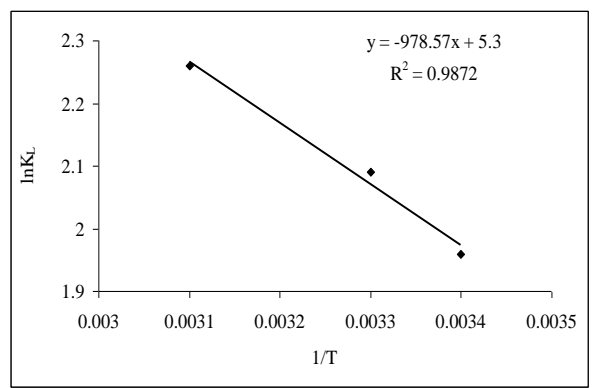

Fig. 5. Plot of $\operatorname{lin} K_{L}$ vs $1 / T$ for estimation of thermodynamic parameters for biosorption of cadmium cations onto Acacia tortilis seeds.

\section{H. Comparison of Acacia Tortilis Seeds with Other Adsorbents}

The adsorption capacity of different low cost adsorbents used for removal cadmium from aqueous solutions was compared with Acacia tortilis seeds (this study) and presented in Table VI.

TABLE VI: COMPARISON OF ACACIA TORTILIS SEEDS WITH OTHER LOW COST ADSORBENTS

\begin{tabular}{lc}
\hline \hline Adsorbent & $q_{e}(\mathrm{mg} / \mathrm{g})$ \\
\hline Acacia tortilis seeds & 807 \\
Coconut copra meal & 1.84 \\
Hazelnut shell & 5.42 \\
Almond shell & 3.18 \\
Rice husk & 8.58 \\
Saw dust & 0.29 \\
Rice polish & 9.72 \\
Wheat bran & 0.7 \\
Cassava waste & 18.05 \\
Mungbean husk & 35.41 \\
Spent grain & 17.3 \\
Olive cake & 10.56 \\
Pine bark char & 0.34 \\
\hline \hline
\end{tabular}

As shown in Table VI, Acacia tortilis seeds may be classified as a highly efficient adsorbent when compared to other low cost adsorbents [8]. 


\section{CONCLUSION}

In this work, the ability of Acacia tortilis seeds to remove the synthetic cadmium cations from water has been demonstrated. The seeds were characterized by measuring the cellulose content, solubility in water, surface area and pore volume. In this batch mode of studies, the adsorption depended on the contact time, initial $\mathrm{pH}$ and contact temperature. The results of the study revealed that the removal of cadmium cations from aqueous solution by Acacia tortilis seeds seems to follow the pseudo-second order kinetic model and the Freundlich isotherm model better than the Langmuir isotherm model.

High temperature favored the biosorption of cadmium cations as the process was found to be endothermic. The biosorption process was found to be spontaneous for the cadmium cations as evident in the negative $\Delta G^{\circ}$ values obtained at all contact temperatures. The Acacia tortilis seeds may be classified as a highly efficient adsorbent when compared to many other low cost adsorbents.

\section{REFERENCES}

[1] T. Qiang, T. Yiaowu, H. Manman, L. Zhenze, C. Yunmin, and L. Peng, "Removal of Cd(II) from aqueous solution with activated Firmiana Simplex Leaf: Behaviours and affecting factors," Journal Hazard Material, vol. 179, pp. 95-103, February 2010.

[2] M. M. Rao, A. Ramesh, G. P. C. Rao, and A. Seshaiah, "Removal of copper and cadmium from aqueous solutions by activated carbon derived from ceiba pentandra hulls," Journal Hazard Material B, vol. 129, pp. 123-139, September 2005.

[3] G. Farshid, Y. Habibollah, and M. G. Seyed, "Application of response surface methodology for optimization of cadmium biosorptionin an aqueous solution by Saccharomyces cerevisia," Chemical Engineering Journal, vol. 145, pp. 267-275, April 2008.

[4] M. A. Ackacha and S. A. Meftah, "Elimination of Cu (II) cations from water media using clean adsorbent as application of green chemistry: Acacia tortilis seeds," Journal of Clean energy Technologist, vol. 1, no. 1, pp. 57-61, January 2013.

[5] A. Hashem and M. M. Elhmmali, "Modification of sodium alginate for the removal of $\mathrm{Cd}$ (II) from aqueous solution, Polymer-Plastics Tehnology and Engineering, vol. 45, pp. 707-712, 2006.

[6] M. A. Ackacha, "Removal of Zn (II) ions from aqueous solution by new adsorbent: Calligonum comosum," International Journal of Chemical and Environmental Engineering, vol. 1, no. 1, pp. 18-22, July 2010.

[7] B. Noroozi, G. A. Sorial, H. Bahrami, and M. Arami, "Equilibrium and kinetic adsorption study of a cationic dye by a natural adsorbent-Sikworm pupa," Journal Hazard Material B, vol. 139, pp. 167-174, June 2006.
[8] F. Y. Wang, H. Wang, and J. W. Ma, "Adsorption of cadmium (II) ions from aqueous solution by a new low cost adsorbent-Bamboo charcoal," Journal Hazard Material, vol. 177, pp. 300-306. December 2009.

[9] M. Alexander, Introduction in Soil Microbiology, Jon\&Sons, $2^{\text {nd }}$ ed. 1982, pp. 573.

[10] M. Zabihi, A. H. Asi, and A. Ahmadpour, "Studies on adsorption of mercury from aqueous solution on activated carbon prepared from wahnut shell," Journal Hazard Material, vol. 174, pp. 251-256, September 2010.

[11] M. A. Ackacha and S. A. Elmahdy, "Utilization of activated carbon derived from date stones to reduce lead and cadmium from aqueous solutions," in Proc. $2^{\text {nd }}$ ICEST Conf. Environmental Science and Technology, Singapore, 2011, pp. 40-44.

[12] M. H. Kalavathy and L. R. Mirand, "Comparison of copper adsorption from aqueous solution using modified and modified Hevea brasiliensis saw dust," Desalination, vol. 255, pp. 165-174, February 2010.

[13] Q. Li, J. Zhai, W. Zhang, M. Wang, and J. Zhou, "Kinetic studies of Adsorption of $\mathrm{Pb}$ (II), Cr (III) and $\mathrm{Cu}$ (II) from aqueous solution by sawdust and modified peanut husk," Journal Hazard Material, vol. 141, pp. 163-167, July 2006.

[14] M. Ackacha and R. Azaka, "The use of calligonum comosum as a new adsorbent for the removal of cadmium ions from aqueous solutions," in Proc. CCEA Conf. Chemical Engineering and Applications, Singapore, 2010, pp. 203-208.

[15] S. Dahiya, R. M. Tripathi, and A. G. Hegde, "Biosorption of lead and copper from aqueous solutions by pre-treated crab and arca shell biomass," Bioresouce Technology, vol. 99, pp. 179-187, January 2007.

[16] B. M. W. P. K. Amarasinghe and R. A. Williams, "Tea waste as a low cost adsorbent for the removal of $\mathrm{Cu}$ and $\mathrm{Pb}$ from wastewater," Chemical Engineering Journal, vol. 132, pp. 299-309, January 2007.

[17] M. Ackacha and L. Elsharif, "The use of Acacia tortilis leaves as low cost adsorbent to reduce the lead cations from an aquatic environment," in Proc. ICGES Conf. International Conference on Geological and Environmental Sciences, Jeju Island, South Korea, 2012, pp. 80-84.

[18] S. M. Lee and P. D. Allen, "Removal of Cu (II) and Cd (II) from aqueous solution by seafood processing waste sludge," Water Research, vol. 35, no. 2, pp. 534-340, 2001.

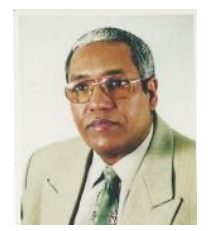

Mohamed Abduelrahman Ackacha was born in Samno, Libya in 1957. He gained B.Sc. in chemistry from Faculty of science, Tripoli University, Libya; M. Sc. in chemistry from Micaway Kopernik University, Torun, Poland; Ph.D. in analytical chemistry from Warsaw University of Technology, Poland. He has the experience in the field of removal of heavy metals and dyes from aqueous media using agricultural materials.

Somaya Abdusalam Meftah was born in sebha, Libya in 1986. He got the B.Sc. from Chemistry Department, Faculty of Science, Sebha University, Libya; M.Sc. in analytical chemistry from Chemistry Department, Faculty of Science, Sebha University, Libya in 2011. The title of his M.Sc thesis is Removal of Some Cationic Materials from Aqueous Solutions Using Natural Treatment of Acacia tortilis as an Application of Green Chemistry. 